\title{
Determinants of and opportunities for continuing education among health care professionals in public health care institutions in Jimma township, Southwest Ethiopia
}

\author{
This article was published in the following Dove Press journal: \\ Advances in Medical Education and Practice \\ 17 September 2012 \\ Number of times this article has been viewed
}

\author{
Netsanet Fentahun' \\ Ashagre Molla ${ }^{2}$ \\ 'Department of Health Education \\ and Behavioral Sciences, ${ }^{2}$ Department \\ of Nursing, Jimma University, \\ Jimma, Ethiopia
}

Background: An effectively prepared and continually updated workforce of health professionals is essential to maintenance and improvement in patient care. The major goal of continuing education is to improve and promote quality care. Continuing education is also important to an organization's strategic plan because of its positive influence on the quality of care provided. The purpose of this study was to identify the determinants of and opportunities for continuing education among health care professionals at public health facilities in Jimma township.

Methods: A cross-sectional study of 319 health care professionals working in the public health facilities of Jimma township was conducted from January 10, 2012 to February 28, 2012. A selfadministered questionnaire was used to collect the data. First, descriptive analysis was done to describe the characteristics of the study participants. Finally logistic regression was then used to determine the independent predictors of continuing education.

Results: Only 70 (25\%) of the study participants were participating in continuing education. As working experience increased, participation in continuing education did not steadily increase. The working hours per week were higher for diploma holders than for those with any other qualification. One hundred and fifty-three (71.8\%) participants mentioned lack of support from their current employer as the reason for not participating in continuing education. Health care professionals with a lack of support from management were 2.4 times more likely not to participate in advanced education. Health care professionals with lack of funding were 0.3 times less likely to participate in advanced education. Health care professionals with lack of resources other than financial were 2.2 times more likely not to participate in advanced education.

Conclusion: Participation of health care professionals in continuing education is low in Jimma township. The hospital management and town health office should support health care professionals in pursuing advanced education.

Keywords: health care professionals, continuing education, public health institution

\section{Introduction}

Continuing education refers to educational activities intended to expand the educational and experience base for health professionals and to strengthen practice, education, administration, research, and theoretical development, with a view to improving the health of patients. ${ }^{1}$ Professional practitioners of any kind must continue to learn because they are accountable to the public for minimum safe practice. Continuing education is needed primarily to keep health care professionals abreast of changes in
Correspondence: Netsanet Fentahun Jimma University, College of Public Health and Medical Sciences, PO Box 378, Jimma, Ethiopia Tel +251913516677

Fax +25 I 47 III I 450

Email netsanet_fentahun@yahoo.com 
their roles and functions, help them to acquire new knowledge and skills, and modify their attitudes and understanding. ${ }^{2}$

Moreover, given the emphasis on evidence-based practice, health professionals constantly need to update their knowledge and professional skills. Therefore, continuing education has increasingly become essential to guarantee high-quality health care practice. ${ }^{3}$ An effectively prepared and continually updated health professional workforce is essential to maintenance and improvement in quality of care. Numerous studies document that quality indicators, such as risk of medication errors, patient falls, pressure sores, and nosocomial infections are markedly reduced by two important factors, ie, ongoing education and adequate numbers of skilled staff. ${ }^{4}$

Health professionals enter the field armed with the knowledge they need to excel in their careers. However, health care is a changing field with constant new developments. Continuing education prepares health professionals for these changes. ${ }^{5}$ If they do not participate in continuing education activities, the quality of care provided by the health professional community would diminish drastically, care would become inconsistent, and dangerous mistakes could easily become commonplace through lack of understanding. Continuing education should serve as a viable means of improving the professional competence of the practitioner with the outcome of improved health care. ${ }^{6}$

Most African countries are continuing to experience new challenges. One such challenge is the scarcity of health workers as a result of low salaries, poor conditions of service, lack of professional updating, and migration to more affluent countries. To address this problem, the governments of the different countries have increased salaries and allowances for health workers and provided other incentives, such as cars, in order to retain those already in the system. ${ }^{7}$ The health policy of Ethiopia emphasizes training of community based task-oriented frontline and mid level health care workers. The World Health Organization has identified a threshold of workforce density below which adequate coverage of essential interventions, including those necessary to meet the health-related Millennium Development Goals, would be very unlikely. ${ }^{8}$

There is limited opportunity to participate in continuing education in Jimma zone and in the Jimma township situated in southwest Ethiopia, and there is no documented information on whether the continuing education being given is consistent with guidelines for professional standards. There has also been an information gap regarding determinants of and opportunities for continuing education of health care providers until now. This study investigated the issue of continuing education for health care professionals working in the public health facilities in Jimma township.

\section{Methods and materials Study area and period}

A facility-based cross-sectional study was performed from January 10, 2012 to February 28, 2012 in Jimma township, southwest Ethiopia, which is located $346 \mathrm{~km}$ from Addis Ababa. The study was conducted among health care professionals working in two public health centers and at Jimma University Specialized Hospital. This hospital is the only teaching and referral institution in the southwestern part of the country, and provides specialized health services via its nine medical and other clinical and diagnostic departments for approximately 9000 inpatients and 80,000 outpatients each year. Its workforce consists of more than 550 professionals of different disciplines. The Jimma Health Center currently has 18 health care professionals and 15 administrative staff, and the Higher 2 Jimma Maternal and Child Health Center consists of 16 heath care professionals and 15 administrative staff.

\section{Source and study population}

All health professionals involved in direct provision of clinical services at the public health service institutions in Jimma township participated in this study. A total of 319 health care professionals were invited to participate.

\section{Instruments and measurement}

A structured English questionnaire was adapted from the literature, $9,16,22$ with subsections canvassing personal factors, professional factors, organizational factors, and continuing education. The nature of the questionnaire was yes/no and multiple choices. The content validity of the questionnaire was assured by experts. Six data collectors and three supervisors participated in the process of data collection. All data collectors and supervisors had a BSc qualification in health education and nursing. The questionnaire was given personally and collected immediately.

Before the actual data collection, the questionnaire was tested in $5 \%$ of the total sample. The study participants taking part in the pretest were not included in the main study. The study was conducted at Serbo Health Center, which has characteristics similar to those of the main study participants.

The data collectors introduced themselves to study participants and outlined the purpose of the study. 
The questionnaire was adapted from similar studies and modified based on our objective to assure the content validity of the data. Training of the data collectors and supervisors was conducted under close supervision. The questionnaire was also pretested.

\section{Data analysis}

The data were checked and edited before being entered into Statistical Package for Social Sciences version 16.0 software (SPSS Inc, Chicago, IL). Before the analysis, we checked the assumptions made, the nature of the variables, and rearrangement of these variables. First, descriptive analysis was done to describe the characteristics of the study participants. Next, logistic regression was used to determine independent predictors of continuing education. Finally, independent variables which had a statistically significant association with the dependent variable $(P<0.05)$ were entered to the regression model. Ethical permission was obtained from the ethics committee of the College of Public Health and Medical Science, Jimma University. After obtaining ethical permission, written permission was obtained from Jimma University Specialized Hospital, Jimma Health Center, and the Jimma Higher 2 Maternal and Child Health Center, and verbal informed consent was obtained from each study subject.

\section{Results}

A total of 281 staff participated in this study, with a response rate of $88 \%$. The mean age of respondents was $31.5 \pm 9.2$ years. Of the 281 study participants, 154 (54.8\%) were males and $128(45.6 \%)$ were Oromo in ethnicity. Almost half of the respondents (48.4\%) were married and about three quarters were nurses. One hundred and fifty-one $(53.7 \%)$ respondents had a diploma qualification. The working experience of the study participants was 1-35 (mean $8.4 \pm 8.6)$ years. Seventy-one subjects $(25.3 \%)$ had $3-4$ years of working experience.

Hours worked per week were 32-96 (mean $51.7 \pm 13.9$ ). One hundred and twelve (39.9\%) health care professionals worked $\leq 40$ hours per week, whereas $22.2 \%$ worked $\geq 57$ hours per week. One hundred and twenty-three participants (43.8\%) had children; of these, $32.5 \%$ had under five children (Table 1).

Two hundred and eleven (75\%) respondents did not participate in continuing education. Only 70 (25\%) did participate (Figure 1). Participating in continuing education did not increase steadily as working experience increased. Health professionals who had 7-8 years and more than
Table I Sociodemographic characteristics of study participants at public health institutions in Jimma township, February 2012

\begin{tabular}{|c|c|c|c|}
\hline \multirow[t]{2}{*}{ Characteristics } & \multirow[t]{2}{*}{ Categories } & \multicolumn{2}{|c|}{ Frequency } \\
\hline & & $\mathbf{n}$ & $\%$ \\
\hline \multirow[t]{6}{*}{ Mean age $31.5 \pm 9.2$ years } & $20-24$ & 72 & 25.6 \\
\hline & $25-29$ & 94 & 33.5 \\
\hline & $30-34$ & 34 & 12.1 \\
\hline & $35-39$ & 20 & 7.1 \\
\hline & $40-44$ & 24 & 8.5 \\
\hline & $\geq 45$ & 37 & 13.2 \\
\hline \multirow[t]{2}{*}{ Gender } & Male & 154 & 54.8 \\
\hline & Female & 127 & 45.2 \\
\hline \multirow[t]{6}{*}{ Ethnicity } & Oromo & 128 & 45.6 \\
\hline & Amhara & 76 & 27.0 \\
\hline & Gurage & 18 & 6.4 \\
\hline & Tigre & 10 & 3.6 \\
\hline & Dawro & 15 & 5.3 \\
\hline & Others* & 34 & 12.1 \\
\hline \multirow[t]{4}{*}{ Marital status } & Married & 136 & 48.4 \\
\hline & Divorced & 7 & 2.5 \\
\hline & Widowed & 6 & 2.1 \\
\hline & Single & 132 & 47.0 \\
\hline \multirow[t]{7}{*}{ Current profession } & Pharmacist & 24 & 8.5 \\
\hline & Medical laboratory & 26 & 9.3 \\
\hline & Health officer & 9 & 3.2 \\
\hline & Nurse & 207 & 73.7 \\
\hline & Radiologist & 8 & 2.8 \\
\hline & Environmental health & 4 & 1.4 \\
\hline & Others** & 3 & 1.1 \\
\hline \multirow[t]{4}{*}{ Level of education } & Diploma & $|5|$ & 53.7 \\
\hline & Advanced diploma & 16 & 5.7 \\
\hline & Degree & 112 & 39.9 \\
\hline & Others & 2 & 0.7 \\
\hline \multirow[t]{4}{*}{ Monthly salary (Birr) } & $\leq 1427$ & 82 & 29.2 \\
\hline & $1428-1800$ & 64 & 22.8 \\
\hline & $|80|-2250$ & 77 & 27.4 \\
\hline & $\geq 225$ I & 58 & 20.6 \\
\hline Mean years of experience, & $\leq 2$ & 65 & 23.1 \\
\hline \multirow[t]{5}{*}{$8.4 \pm 8.6$} & $3-4$ & 71 & 25.3 \\
\hline & $5-6$ & 33 & 11.7 \\
\hline & $7-8$ & 30 & 10.7 \\
\hline & $9-10$ & 18 & 6.4 \\
\hline & $\geq 11$ & 64 & 22.8 \\
\hline Mean hours worked per week, & $\leq 40$ & 112 & 39.9 \\
\hline \multirow[t]{3}{*}{$51.7 \pm 13.9$} & $4 I-48$ & 48 & 17.1 \\
\hline & $49-56$ & 57 & 20.3 \\
\hline & $\geq 57$ & 64 & 22.8 \\
\hline Mean age of youngest child, & $\leq 1$ & 22 & 17.9 \\
\hline \multirow[t]{4}{*}{$8.6 \pm 6.8$ years $(n=123)$} & $1-4$ & 18 & 14.6 \\
\hline & $5-9$ & 28 & 22.8 \\
\hline & $10-19$ & 49 & 39.8 \\
\hline & $\geq 20$ & 6 & 4.9 \\
\hline
\end{tabular}

Notes: *Yem, kafficho, silte, koorete; **optometry.

Abbreviations: SD, standard deviation; Birr, Ethiopian Birr (\$US I = 17.85 Ethiopian Birr).

11 years of working experience had a greater chance to participate in continuing education. When compared with other health care professionals, nurses were less likely to participate in continuing education. Of the 281 health care 


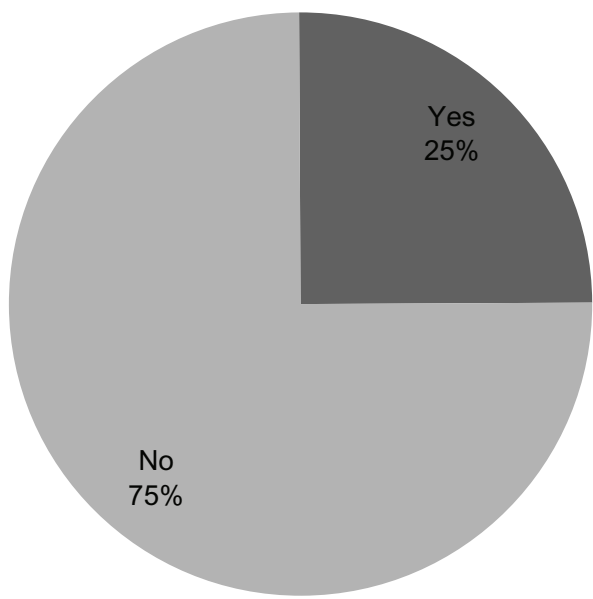

Figure I Distribution of participation in advanced education/continuing education among participants in public health institutions at Jimma township, February 2012.

professionals, $146(52 \%)$ had both basic and advanced education through self-funding and $113(40 \%)$ through full funding. There was limited chance of getting sponsorship to obtain advanced education. A significant number of professionals worked $<40$ hours per week. Significant numbers of nurses worked less than 40 hours or $\geq 57$ hours per week. This indicates that a considerable number of participants were working fewer than normal working hours. In comparison with other disciplines, nurses worked more hours per week (Figure 2).

Diploma holders worked more hours per week than holders of degrees. Of 112 health care professionals who had a first degree, $60(53.6 \%)$ worked $\leq 40$ hours per week. Of 151 who had a diploma qualification, 48 (31.8\%) worked $\leq 40$ hours per week. These figures indicate that working hours per week decreased as educational status increased (Figure 3 ). Of the 70 health care professionals with advanced education, $40(57.1 \%)$ reported better performance in their present job, and $12(17 \%)$ did not report any benefit (Table 2).

Regarding reasons cited for not participating in continuing education, $153(71.8 \%)$ respondents mentioned lack of support from their current employer, whereas 90 (42.3\%) mentioned lack of funds and 20 (9.4\%) cited lack of the necessary prerequisites for participation (Table 3 ).

One hundred and forty-six (63\%) of the participants preferred a regular program to advance their education and $43(18 \%)$ preferred a summer program. Thirty-seven (16\%) respondents wanted to advance their education through an extension program. The order of preference to advance their education, from highest to lowest frequency, was regular, summer, extension, and distance (Figure 4).

Logistic regression analysis was done to identify the effect of independent variables on continuing education, and this showed that health care professionals with lack of support from management were 2.4 times more likely not to participate in advanced education (odds ratio 2.4) than those with support from management. This implies that those who had the support of management had a better probability of participating in continuing education. Health care professionals with lack of funding were 0.3 times more likely to participate in advanced education (odds ratio 0.3 ) than those

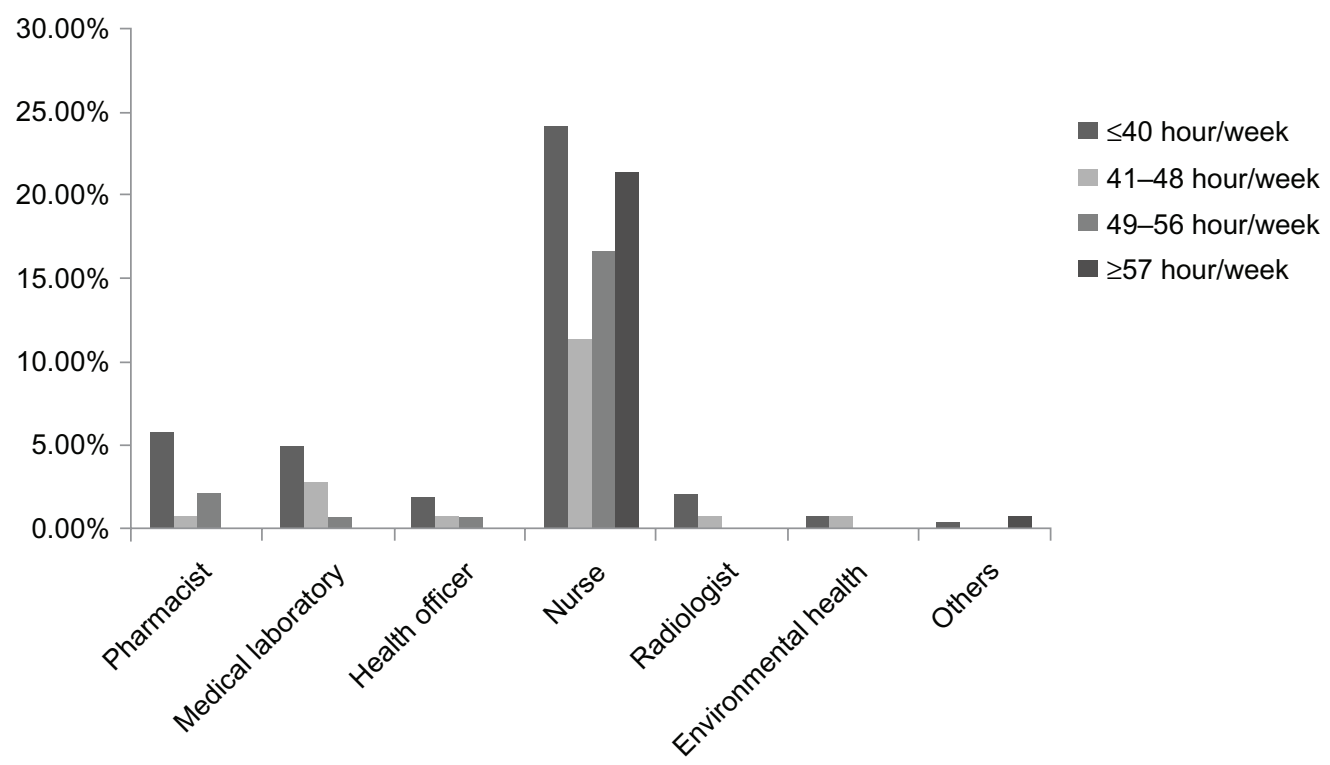

Figure 2 Distribution of health professionals by working hours per week in public health institutions at Jimma township, February 2012. 


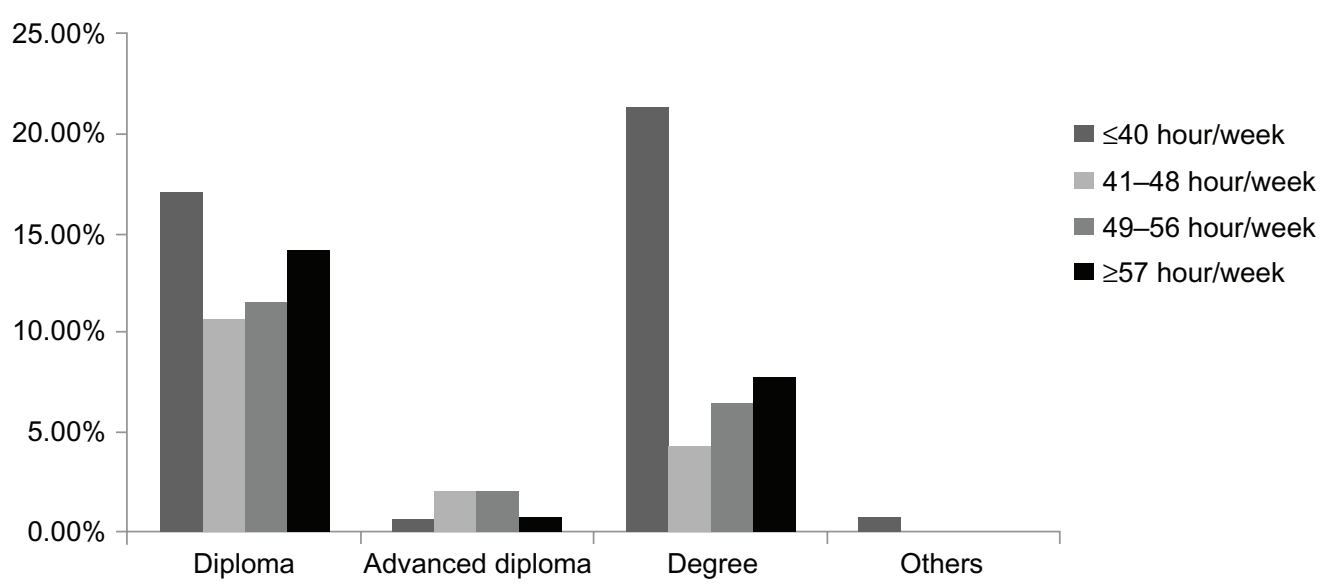

Figure 3 Distribution of participants according to academic qualification and working hours per week in public health institutions at Jimma township, February 2012.

with funding available. This implies that lack of funding did not prevent health care professionals from participation in advanced education.

Health care professionals with lack of resources were 2.2 times more likely not to participate in advanced education (odds ratio 2.2) than those with resources. Health care professionals with working experience of 7-8 years were 0.1 times more likely to participate in advanced education (odds ratio 0.1 ) than those who had $\leq 2$ years of working experience. Health care professionals with a monthly salary $\geq 2251$ Ethiopian Birr were 0.4 times more likely to participate in advanced education (odds ratio 0.4 ) than those with a monthly salary $\leq 1427$ Birr. Health care professionals who were married were 0.4 times more likely to participate

Table 2 Benefits obtained by participating in advanced education among participants working in public health institutions of Jimma township, February 2012

\begin{tabular}{lll}
\hline Benefit from advanced education $(\mathbf{n}=\mathbf{7 0})$ & Frequency & $\%$ \\
\hline Getting new job & & \\
$\quad$ Yes & 12 & 17.1 \\
No & 58 & 82.9 \\
Higher salary & & \\
$\quad$ Yes & 28 & 40 \\
No & 42 & 60 \\
Better performance in present job & & \\
Yes & 40 & 57.1 \\
No & 30 & 42.9 \\
Personal reasons (meet other people, refresh skills) & & \\
Yes & 18 & 25.7 \\
No & 52 & 74.3 \\
Promotion in the jobs & & \\
Yes & 18 & 25.7 \\
No & 52 & 74.3 \\
No outcomes yet & & \\
Yes & 12 & 17 \\
No & 58 & 83 \\
\hline
\end{tabular}

in advanced education (odds ratio 0.4 ) than those who were single (Table 4).

\section{Discussion}

The findings of this study show that only $25 \%$ of the participants were involved in continuing education. This implies that the majority are not updating themselves. Not participating in advanced education has a negative effect on quality of health care. This result is very low when compared with a study conducted in Mexican health institutions. ${ }^{9}$ This may be due to differences between the two studies concerning accessibility of continuing education opportunities and awareness of participants about the importance of continuing education.

More than half of the respondents (57.1\%) cited a desire to perform better in their present job as their reason for

Table 3 Reasons given by participants for not being involved in continuing education in public health institutions of Jimma township, February 2012

\begin{tabular}{lll}
\hline Reasons for not participating & Frequency & $\%$ \\
\hline Lack of support from current employer & & \\
$\quad$ Yes & 153 & 71.8 \\
$\quad$ No & 60 & 28.2 \\
Lack of funds & & \\
$\quad$ Yes & 90 & 42.3 \\
No & 123 & 57.7 \\
Lack of appropriate courses & & \\
Yes & 40 & 18.8 \\
No & 173 & 81.2 \\
Lack of time/study leave & & \\
Yes & 34 & 16 \\
No & 179 & 84 \\
Lacking prerequisite & & \\
Yes & 20 & 9.4 \\
No & 193 & 90.6 \\
\hline
\end{tabular}




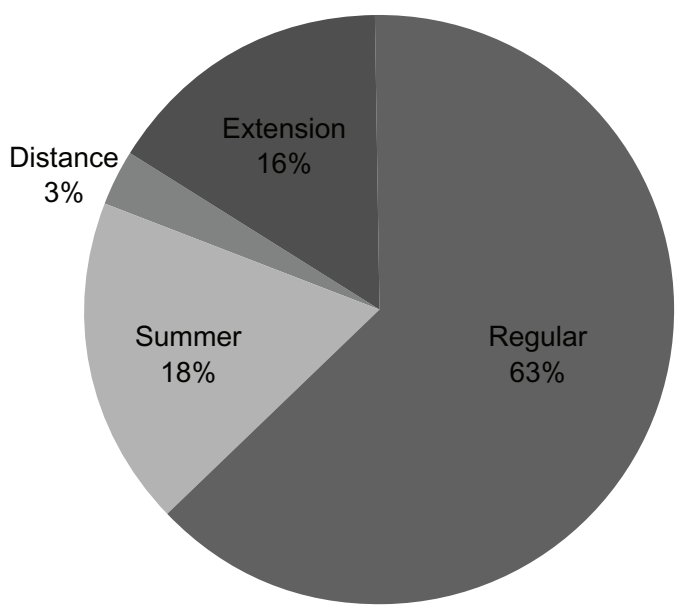

Figure 4 Programs attended by participants receiving advanced education in public health institutions at Jimma township, February 2012.

participating in continuing education. Better performance has a direct impact on building trust on the part of patients and quality of health care on the part of the organization. Educational programs increase knowledge and skills in order to deliver health care of adequate quality. Health care professionals participating in continuing education tend to perform better. This result is supported by study findings in the US, Uganda, and Canada. ${ }^{10-12}$

The second most commonly cited reason for participating in continuing education in our study was to get a higher salary $(40 \%)$. This implies that education not only helps to motivate health professionals to do their work effectively, but also that health care professionals consider salary to be a motivator for continuing education. This finding is different from that in a similar study conducted in the Faculty of Nursing, University of Toronto, in Canada. ${ }^{13}$ A possible reason for the difference might be different socioeconomic characteristics and health care workloads. The reasons given for participating in continuing education in this study almost coincide with the reasons given by participants in a study conducted in Ghana. ${ }^{14}$ These consistencies may be due to the socioeconomic similarities of participants of these studies.

Of those involved in continuing education, about one fifth (17\%) reported no benefit from the continuing education they had received. This indicates that people may not get the opportunity to work in the specialty or discipline they have trained for. Another implication is that human resources are perhaps not being utilized properly.

Among the reasons for not participating in advanced/ continuing education, lack of support from the current employer was the main reason given by $71.8 \%$ of participants. This finding is critical because the employer has an
Table 4 Multiple logistic regression for advanced education among study participants in public health institutions in Jimma township, February 2012

\begin{tabular}{|c|c|c|c|}
\hline \multirow[t]{2}{*}{ Variables } & \multicolumn{2}{|c|}{ Advanced education } & \multirow[t]{2}{*}{ AOR } \\
\hline & Yes & No & \\
\hline \multicolumn{4}{|c|}{ Lack of support } \\
\hline \multicolumn{4}{|c|}{ from management } \\
\hline Yes & 44 & 147 & $2.4^{*}$ \\
\hline No* & 26 & 64 & I \\
\hline \multicolumn{4}{|l|}{ Lack of funds } \\
\hline Yes & 45 & 94 & $0.3^{*}$ \\
\hline No* & 25 & 117 & I \\
\hline \multicolumn{4}{|c|}{ Lack of staff cover } \\
\hline Yes & 21 & 72 & 1.17 \\
\hline No* & 49 & 139 & I \\
\hline \multicolumn{4}{|c|}{ Lack of resources } \\
\hline Yes & 15 & 73 & $2.2^{*}$ \\
\hline No* & 55 & 138 & 1 \\
\hline \multicolumn{4}{|l|}{ Lack of time } \\
\hline Yes & 11 & 32 & 1.7 \\
\hline No* & 59 & 179 & I \\
\hline \multicolumn{4}{|c|}{ Years of experience } \\
\hline$\leq 2 *$ & 8 & 57 & I \\
\hline $3-4$ & 14 & 57 & 0.8 \\
\hline $5-6$ & 6 & 27 & 1.4 \\
\hline $7-8$ & 16 & 14 & $0.1 *$ \\
\hline $9-10$ & 6 & 12 & 0.5 \\
\hline$\geq I I$ & 20 & 44 & 0.5 \\
\hline \multicolumn{4}{|l|}{ Monthly salary } \\
\hline$\leq 1427^{*}$ & 14 & 68 & I \\
\hline $\mid 428-1800$ & 12 & 52 & 1.8 \\
\hline$|80|-2250$ & 18 & 59 & 1.4 \\
\hline$\geq 225 \mathrm{I}$ & 26 & 32 & $0.4 *$ \\
\hline \multicolumn{4}{|l|}{ Marital status } \\
\hline Single* & 20 & 112 & I \\
\hline Married & 46 & 90 & $0.4^{*}$ \\
\hline Divorced & 2 & 5 & $0.1^{*}$ \\
\hline Widowed & 2 & 4 & 0.2 \\
\hline Constant & & & 0.554 \\
\hline
\end{tabular}

Note: *Indicates significant at $P<0.05$.

Abbreviation: AOR, adjusted odds ratio.

important role in encouraging and facilitating professional development for employees and in investing social capital to ensure that professional learning occurs in the workplace. These findings are similar to those of a study conducted in the US. ${ }^{15}$

Lack of funding was the second most common reason given for nonparticipation in advanced or continuing education. This finding is inconsistent with the study done in Canada, where financial constraint was the major determinant of nonparticipation in continuing education. ${ }^{16}$ This may be due to better employer support and availability of courses/programs appropriate for participants in Canada. Moreover, this finding is very similar to that of a study conducted in the US. ${ }^{13}$ 
A significant proportion of participants cited lack of time or study leave as their reason for not participating in continuing education. This reflects the fact that most of the study participants were diploma holders, who have a greater workload than other health care professionals, and so have limited time to participate in continuing education. This may result in lack of motivation and dissatisfaction on the part of these health care professionals, and lack of quality of care and high staff turnover on the part of the organization. This finding is similar to that in the studies done in Canada and the US..$^{13,17}$

Working hours per week for diploma holders were higher than those for holders of any other health care qualifications. This might be one barrier for professionals holding diplomas in terms of participation in continuing education, and also suggests that health care professionals with advanced education are not being utilizing effectively. Increasing educational level generally results in increased responsibility, but the reverse was true in this study, suggesting that management is focusing on quantity rather than quality of health services. This study finding is different from that of the study conducted in the US. ${ }^{18}$ Possible reasons might be differences in socioeconomic status, types of cases managed, commitment of health professionals, and human resource management between the two countries.

Professionally, nurses participated less than other professionals in continuing education $(60.9 \%)$. This might be due to the fact that most of the respondents of this study were nurses (73.7\%). Possible reasons include lack of opportunity, lack of support from the employer, and personal and/or motivational factors. Discriminating health care professionals participating in continuing education may create some gaps in their disciplines. This may conflict with the team approach in the health care system. Even though professional associations recommend a baccalaureate degree as a minimum requirement for professional nursing practice, ${ }^{19}$ such a larger figure of nonparticipation indicates difficulty might face to upgrade those professionals within short period.

Support from management and availability of resources other than financial support have a positive effect on rates of participation in continuing education. Financial support is clearly an encouraging factor. This indicates that the presence of managerial support and availability of resources like health care professionals that take off the duty of the others and time has great impact on the participation of health care professionals in continuing education.

The absence of financial support does not have a negative effect on continuing education. However, management support in creating opportunities for continuing education is mandatory. This is supported by research underscoring the importance of encouraging and facilitating professional development for individuals. ${ }^{10,15,18}$ However, the findings regarding financial support in this study are different from those in the study reported by Ting. ${ }^{18}$

Health care professionals with working experience of 7-8 years were more likely to participate in advanced education than those who had $\leq 2$ years of working experience. This indicates that working experience is a positive factor for continuing education. As working experience increased, participation in continuing education did not steadily increase, but it is not significant across with working experience.

Health care professionals with a monthly salary $\geq 2251$ Ethiopian Birr were more likely to undertake advanced education than those with a monthly salary $\leq 1427$ Birr. This indicates that health care professionals with a monthly salary $\geq 2251$ Birr can afford to participate in continuing education if the opportunity is available. Generally, selffunded continuing education can be the alternative for such types of health care professionals. The finding is similar to that of the research conducted in Canada, the US, and Mexico. ${ }^{9,13}$

Married health care professionals were more likely to participate in advanced education than those who were single. A possible reason for this might be to provide their children with a role model, to fulfill the physiological needs of the family, and improve their social standing in the community. This finding is similar to that in the study conducted by Penz. ${ }^{21,22}$

\section{Conclusion}

The participation of health professionals in continuing education is low in this region of Ethiopia. The majority of the study participants who advanced their education did so through self-funding. More than half of the participants involved in continuing education felt that they performed better in their present job. Of those who were involved in continuing education, about one-fifth did not get any benefit from what they had learnt.

Nearly three quarters of the participants who are not involved in continuing education cited lack of support from their employer as the main reason for not participating in continuing education. The second most common reason for not participating in continuing education was lack of funding.

The high number of hours worked per week by diploma holders is one of the barriers to participation in continuing education. Nurses participated the least in continuing education when compared with other professionals. The majority 
of participants wanting to undertake continuing education preferred to do so as part of a regular program. Support from management, availability of resources, working experience, monthly salary, and marital status were independent predictors of undertaking continuing education.

Participation of health professionals in continuing education should be improved and strengthened. Hospital management and the town health office should support health professionals to continue their education. Regular, summer, and educational extension programs should be considered and developed for professionals to continue their education. The institution should utilize or assign professionals who have finished their advanced education to appropriate tasks and with reasonable working hours. Support from management, funding for continuing education, provision for study leave, appropriate shift work, and staff cover are recommended to encourage and help professionals wanting to participate in continuing education.

\section{Acknowledgment}

We acknowledge the assistance of Jimma University in undertaking this research. We would also like to express our gratitude to the executive bodies of Jimma University Specialized Hospital, Jimma Health Center, and Jimma Higher 2 Jimma Maternal and Child Health Center, and to the study participants. Our thanks also go to the data collectors and supervisors.

\section{Disclosure}

The authors declare that they have no conflicts of interest in this work.

\section{References}

1. Furze G, Pearcey D. Continuing education in nursing: a review of the literature. J Adv Nurs. 1999;29(2):355-363.

2. Young Kelly L, Solomon Cohen S. The Nursing Experience Trends, Challenges and Transitions. New York, NY: McGraw Hill; 1992.

3. Bartels JE. Educating nurses for the 21st century. Nurs Health Sci. 2005;7(4):221-225.

4. Levett-Jones TL. Continuing education for nurses: a necessity or a nicety? J Contin Educ Nurs. 2005;36(5):229-233.

5. Upson M. Importance of continuing education in nursing. Available from: http://www.ehow.com/about_6325006_importance-continuingeducation-nursing.html. Accessed June 19, 2011.

Advances in Medical Education and Practice

\section{Publish your work in this journal}

Advances in Medical Education and Practice is an international, peerreviewed, open access journal that aims to present and publish research on Medical Education covering medical, dental, nursing and allied healthcare professional education. The journal covers undergraduate education, postgraduate training and continuing medical education
6. Indiana State Nurses Association. Continuing education philosophy: Available from: http://www.indiananurses.org/education/philosophy. htm. Accessed August 24, 2011.

7. Landon B, Loudin J, Selle M, Doucette S. Factors influencing the retention and attrition of community health aides/practitioners in Alaska. J Rural Health. 2004;20(3):221-223.

8. World Health Organization. Working together for health, World Health Report. 2006. Available from: http://www.who.int/whr/2006/ whr06_en.pdf. Accessed August 24, 2011.

9. Flores Peña Y, Alonso Castillo M. Factors influencing nursing staff members' participation in continuing education. Rev Lat Am Enfermagem. 2006;14(3):309-315.

10. Fleet LJ, Louise N, Rita S. Continuing Professional Development and Social Accountability: A Review of the Literature. University of Toronto, Mississauga, ON: Office of Professional Development and Conferencing Services; 2008.

11. Ofosu C, Mallette C. Continuing Education in Nursing. University of Toronto, Mississauga, ON, 1998. Available from: http://fhs.mcmaster. $\mathrm{ca} / \mathrm{nru} /$ Working\%20Papers\%20\&\%20Fact\%20Sheets/factsheets/ Continuing\%20Education\%20in\%20Nursing.pdf. Accessed August 24, 2011.

12. Aiga H. Reasons for participation in and needs for continuing professional education among health workers in Ghana. Health Policy. 2006;77(3):2290-2303.

13. Munro KM. Continuing professional development and the charity paradigm: interrelated individual, collective and organizational issues about continuing professional development. Nurse Educ Today. 2008; 28(8):953-961.

14. Hager M, Russell S, Fletcher SW, editors. Continuing Education in the Health Professions: Improving Healthcare through Lifelong Learning. Proceedings of a conference sponsored by the Josiah Macy Jr Foundation, November 28 to December 1, 2007, Bermuda, FL. New York, NY: Josiah Macy Jr Foundation; 2008.

15. Penz K, D’Arcy C, Stewart N, Kosteniuk J, Morgan D, Smith B. Barriers to participation in continuing education activities among rural and remote nurses. J Contin Educ Nurs. 2007;38(2):58-66.

16. Rubenson K. Barriers to participation in adult education. Available from: http://american-education.org/adult-education/2503-barriers-toparticipation-in-adult-education.html. Accessed June 15, 2012.

17. Bartels JE. Educating nurses for the 21st century. Nurs Health Sci. 2005; 7(4):221-225.

18. Ting VJ. An assessment of factors influencing Illinois registered nurse participation in continuing education (Abstract). Available from: http:// gradworks.umi.com/33/11/3311021.html. Accessed May 28, 2012.

19. Penz K, D’Arcy C, Stewart N, Kosteniuk J, Morgan D, Smith B. Barriers to participation in continuing education activities among rural and remote nurses. J Contin Educ Nurs. 2007;38(2):58-66.

20. Stolee P, Esbaugh J, Aylward S, et al. Factors associated with the effectiveness of continuing education in long-term care. Gerontologist. 2005;45(3):399-409.

21. Penz K, D’Arcy C, Stewart N, Kosteniuk J, Morgan D, Smith B. Barriers to participation in continuing education activities among rural and remote nurses. J Contin Educ Nurs. 2007;38(2):58-66.

22. Stolee P, Esbaugh J. Factors associated with the effectiveness of continuing education in long-term care. Western Centre for Continuing Studies, University of Western Ontario. The Gerontologist. 2005;45(3):399-405.

\section{Dovepress}

including emerging trends and innovative models linking education, research, and healthcare services. The manuscript management system is completely online and includes a very quick and fair peer-review system. Visit http://www.dovepress.com/testimonials.php to read real quotes from published authors. 